\section{Rural development: how to measure performance imbalances in agribusiness chains}

\section{Molnár Adrienn - Gellynck, Xavier}

Ghent University, Faculty of Bioscience engineering, Department Agricultural Economics, Gent

Adrienn.Molnar@Ugent.be

\title{
INTRODUCTION
}

Organizations no longer compete as independent entities, but as supply chains (Christopher, 1998; Cox, 1999; Lambert and Cooper, 2000), and these organizations realize more and more the performance potential of supply chains (Pearson and Samali, 2005; Gellynck et al., 2006). Being part of a well-performing supply chain generates important performance benefits for the individual organization (Zhenxin et al., 2001). As a result, there is an increasing interest in the performance of supply chains as a research subject (Beamon, 1998).

A vast group of authors (Neely et al., 1994, 1995; Beamon, 1998; Christopher, 1998; Beamon, 1999; Li and O'Brien, 1999; Van der Vorst, 2000; Gunasekaran et al., 2001, 2004; Lambert and Pohlen, 2001; Van Der Vorst, 2006) endorses the need to address the measurement of supply chain performance. Nonetheless, previous studies on supply chain performance have considered multiple individual supply chains, but rather compared groups of supply chain members. Some notable exceptions of such analysis are Spekman et al. (1998), Lu et al. (2006) or Clare et al. (2002). As for measuring the performance of supply chains active in the agri-business sector or in the traditional food [2] sector in particular, (Aramyan, 2007) notes a number of challenges. First, this type of firm does not typically gauge their performance in a standardized way which allows comparison (Collins et al., 2001), implying the collection of secondary data from these firms is highly challenging. Furthermore, supply chains belonging to different sectors may have different characteristics such as supply chain length, closeness of supply chain relationships and types of process links (Lambert and Cooper, 2000) possibly influencing their performance. Consequently, supply chain performance measurement, being carried out in other sectors, might reveal differences when compared to performance measurement of traditional food supply chains. Therefore, traditional food as a potential focus on supply chain performance measurement cannot remain neglected.

The above illustrates the interest in research on measuring supply chain performance which motivates the focus of this chapter. Specifically, in this chapter, I present results which contribute to an understanding of the challenges in measuring supply chain performance in the traditional food sector. In particular, I consider supply chain member assessments of their supply chain partner contribution to their own and supply chain performance. The chapter is structured as follows: in the following part, the methodology of the chapter is presented. Next, the research results are discussed and finally conclusions are drawn as well as further research topics formulated.

\section{MATERIALS AND METHODS}

\section{Research method and research sample}

Quantitative data were collected via individual interviews with 270 companies from 3 European countries (Belgium, Hungary, Italy) representing 6 traditional food subsectors (cheese, beer, white pepper, dry sausage, bakery, and ham). The selection of the countries was motivated by the objective to cover a wide geographical diversity in Europe. In these countries, traditional food subsectors were selected based on their socio-economic importance (number and size of enterprises, employment rates, value added, turnover, investments, import/export, and consumption rates) and on facilitating cross product (e.g. Belgian cheese with Belgian beer) and cross-country (e.g. Belgian cheese with Italian cheese) comparison.

The choice for the traditional food sector was on the one hand motivated by the little past attention in scientific literature, while on the other hand by its particularities possibly influencing performance. For instance, the presence of institutional arrangements, that are set up on a collective basis (e.g. protected designations of origin (PDO) certification) (Chappuis and Pierre, 2000) has important consequences for supply chain performance measurement, thinking of the chance for free riding on the collective reputation (Raynaud et al., 2005). Felföldi (2009) found that in order to enhance supply chain performance, it is essential to balance the power distortions between supply chain members. This factor might be putting one out of business from strategic point of view. The ongoing concentration in the retail sector generates a weak market power in the supply side of the sector. That forces short time thinking and solutions. Further, traditional food supply chains typically represent local orientation and such production specifications which are extremely interesting from a consumer perspective (Torjusen et al., 2001). Therefore, the focus lies on the traditional food sector.

Traditional food products are defined according to four criteria: (1) the key production steps are performed in a recognizable national, regional or local area, 2) the product is authentic in itself a) recipe and/or b) raw material and/or c) production process, 3) the product is commercially available for at least 50 years and (4) the product has a unique and memorable gastronomic identity based on which the product is part of the gastronomic heritage. These criteria were developed by the researchers of the TRUEFOOD project based on definitions of PDO, PGI, TSG, regional, local, typical, terroir etc. food products purely for the purpose of harmonized selection of respondents. According to 
this definition, a database of traditional food producers was established.

According to this definition, a database of traditional food producers was established. Next, in each country traditional food SMEs (small and medium sized enterprises) - as food manufacturers - were randomly selected for interviews from the established database. SMEs were defined as companies that employ fewer than 250 people and have a maximum turnover of 50 million EUR. During the interviews with the food manufacturers, each food manufacturer was asked to identify their current most important suppliers and customers. Next, one supplier and one customer were selected and interviewed per food manufacturer. The selection of suppliers and customers was based on the role, place and importance in the traditional food supply chains. For instance, when selecting suppliers, priority was given to suppliers holding a key position in the quality of the processed product such as pig breeders for processed meat and malt-houses for beer. This way, a total of 90 traditional food supply chains (including 90 suppliers, 90 food manufacturers and 90 customers) were created and interviewed. This approach corresponds to the supply chain definition developed by Mentzer et al. (2001), as a supply chain namely consists of a food manufacturer, a supplier, and a customer involved in the upstream and/or downstream flows of products, services, finances, and/or information. The interviews have been carried out between December 2007 and June 2008.

\section{Measurement and scaling}

To measure supply chain performance, respondents (suppliers, food manufacturers, customers) were asked to indicate the extent to which they agree or disagree with 11 statements on five main areas of performance using a seven-point response scale ranging from completely disagree (1) to completely agree (7) (ordinal scores). The 11 statements (the 11 performance items) and the five main areas of performance (the five performance constructs) have been selected based on previous research. The five performance constructs were: 1) Traditionalism, 2) Efficiency, 3) Responsiveness, 4) Quality and 5) Supply chain balance. Within each construct, a set of items addressed specific aspects of these constructs. Together, this set of items is interpreted as providing multiple measures of the underlying performance construct.

As each supply chain analyzed had a supplier, a food manufacturer, and a customer, each item asked these supply chain members to indicate their subjective assessment of the contribution made by other supply chain members to the respondent's performance. Thus, each food manufacturer provided item scores with respect to their individual supplier's and customer's contributions to that food manufacturer's performance (FM_S, FM_C). Similarly, each supplier provided item scores which indicate their perspective on the food manufacturer's contribution to that supplier's performance (S). Finally, each customer provided item scores for the food manufacturer's contribution to the customer's performance (C). These perspectives are summarized in. Since performance can generally be defined as the extent to which goals are achieved
(Kaplan, 1983), the food manufacturer's performance is the extent to which food manufacturer achieves his goals, the supplier's performance is the extent to which the supplier achieves his goals and the customer's performance is the extent to which the customer achieves his goals. Therefore, it is important to note the difference between the performance of the food manufacturer, the supplier and the customer, and the contribution of these chain members to other chain members' performance. Giving a high item score on "Doing business with our supplier helps my company to lower logistic costs significantly" corresponds with a highly perceived contribution of the supplier to lower significantly the food manufacturer's logistic costs. Consequently, it indicates the perceived contribution of the supplier to the food manufacturer's performance, which is not necessarily equal to the performance of the food manufacturer. Similarly, giving a high item score on "Doing business with our supplier helps my company to reduce lead time (time from sending/ getting the request till reply)" corresponds with a high perceived contribution of the supplier to reduce the food manufacturer's lead time, but it does not necessarily reflect a high performance at the level of the food manufacturer's performance. The same approach is used when analysing the relation between the food manufacturer and the customer, and vice versa from the supplier's and customer's perspective in relation to the food manufacturer. For each of the five performance constructs construct scores were computed for each perspective (FM_S, FM_C, S, C) by calculating the median of the item scores for each construct. For each respondent company type, a total performance score was also created, as the median of the 11 performance item scores. We interpret this as an indication of the perception of the performance contribution of the supply chain member to the respondent company's performance.

The constructs of supply chain performance are derived from the SSP paradigm of strategic management, from Transaction Cost Analysis, from the balance theory and the structural hole concept (see Results for further explanation).

\section{Computation of performance differences}

First, supply chain performance is analyzed for each perspective (FM_S, FM_C, S, C) (see table 22). Table 22 presents the median (IQR) for each item and construct.

The choice of using median (IQR) was based on the ordinal nature of the data. Means indicate location estimates which do not exist within the range of the 7 point response scales. More importantly, the difference between estimated medians and mean clearly establish the sample distribution is skewed for most items scores (the median exceeds the mean). Consequently, for the final analysis of supply chain performance, the median and the interquartile range (IQR) are used.

The interquartile range (IQR) is the difference between the $75^{\text {th }}$ and $25^{\text {th }}$ percentile and hence, includes the middle $50 \%$ of all values, ensuring that the results are not influenced by outliers. 
In order to analyze performance differences in the supply chain, we first introduce and use three measures of difference in partner contribution to respondent firm performance. For statistically testing the existence of differences in these performance indicators, Mann and Whitney U tests were used (see table 1). By comparing responses bilaterally, we consider the differing contributions to member performance and, thereby, supply chain performance in its whole.

Definition: dissonance is present in the supply chain when in a pair of members, each member holds a significantly differing perception of the other member's contribution to performance. We examine dissonance for two pairings of supply chain members: FM and S, and FM and $\mathrm{C}$.

We can further differentiate dissonance based on supply chain partners between which it occurs. On the one hand, FM and $\mathrm{S}$ dissonance is present when the perceived contribution of supplier to food manufacturer's performance (FM_S) is significantly different from the perceived contribution of food manufacturer to supplier's performance (S). On the other hand, FM and $\mathrm{C}$ dissonance is present when the perceived contribution of customer to food manufacturer's performance (FM_C) significantly differs from the perceived contribution of food manufacturer to customer's performance $(\mathrm{C})$.

Table 1 .

Performance of the different supply chain members, median and interquartile range (IQR) (n=213)

\begin{tabular}{llllc}
\hline & FM_S a n=71 & FM_C a n=71 & S a n=71 & C a n=71 \\
\hline Performance & Median (IQR) & Median (IQR) & Median (IQR) & Median (IQR) \\
Traditionalism & $6.00(3.00)$ & $5.50(2.50)$ & $6.00(2.50)$ & $6.00(1.50)$ \\
Authenticity & $6.00(2.00)$ & $6.00(3.00)$ & $6.00(3.00)$ & $6.00(2.00)$ \\
Gastronomic heritage & $6.00(3.00)$ & $6.00(3.00)$ & $6.00(2.00)$ & $6.00(2.00)$ \\
Efficiency & $5.00(1.50) \mathrm{b}$ & $5.00(1.50) \mathrm{a}, \mathrm{b}$ & $5.00(1.50) \mathrm{a}$ & $4.50(2.00) \mathrm{a}$ \\
Logistic cost & $5.00(2.00) \mathrm{c}$ & $5.00(2.00) \mathrm{b}, \mathrm{c}$ & $5.00(3.00) \mathrm{a}, \mathrm{b}$ & $4.00(3.00) \mathrm{a}$ \\
Profit & $5.00(1.00)$ & $5.00(2.00)$ & $5.00(2.00)$ & $5.00(2.00)$ \\
Responsiveness & $6.00(1.50) \mathrm{b}$ & $5.50(1.00) \mathrm{a}, \mathrm{b}$ & $5.50(2.00) \mathrm{a}, \mathrm{b}$ & $5.00(1.50) \mathrm{a}$ \\
Lead time & $6.00(2.00) \mathrm{b}$ & $5.00(1.00) \mathrm{a}, \mathrm{b}$ & $6.00(3.00) \mathrm{a}, \mathrm{b}$ & $5.00(2.00) \mathrm{a}$ \\
Customer complaints & $6.00(2.00)$ & $5.00(1.00)$ & $6.00(2.00)$ & $6.00(1.00)$ \\
Quality & $6.00(3.00) \mathrm{b}$ & $5.00(2.00) \mathrm{a}$ & $5.00(2.00) \mathrm{a}$ & $6.00(1.00) \mathrm{a}, \mathrm{b}$ \\
Safety & $7.00(1.25) \mathrm{b}$ & $5.00(2.00) \mathrm{a}$ & $6.00(3.00) \mathrm{a}$ & $6.00(2.00) \mathrm{a}$ \\
Attractiveness & $4.50(2.25) \mathrm{a}$ & $6.00(2.00) \mathrm{b}$ & $4.00(2.00) \mathrm{a}$ & $6.00(1.00) \mathrm{b}$ \\
Environmental friendliness & $5.50(3.00)$ & $5.00(2.00)$ & $5.00(2.00)$ & $4.00(2.00)$ \\
Supply chain balance & $5.00(1.50)$ & $5.50(1.50)$ & $5.00(1.50)$ & $5.00(2.00)$ \\
Distribution of risks \& benefits & $5.00(2.00) \mathrm{a}, \mathrm{b}$ & $5.00(2.00) \mathrm{a}$ & $5.00(2.00) \mathrm{a}, \mathrm{b}$ & $5.00(2.00) \mathrm{b}$ \\
Supply chain understanding & $5.00(2.00) \mathrm{a}, \mathrm{b}$ & $6.00(1.00) \mathrm{a}$ & $5.00(2.00) \mathrm{a}, \mathrm{b}$ & $5.00(2.00) \mathrm{b}$ \\
Total & $6.00(2.00) \mathrm{b}$ & $5.00(1.00) \mathrm{a}$ & & $5.00(2.00) \mathrm{a}$
\end{tabular}

Source: own compilation

Note: a FM_S = Food manufacturers' perception about their suppliers, FM_C = Food manufacturers' perception about their customers, S= Suppliers' perception about their food manufacturers, $\mathrm{C}=$ Customers' perception about their food manufacturers; different letters (a-b-c) indicate significantly different medium scores in one row at 0.05 using Mann-Whitney $\mathrm{U}$ test.

Definition: Supply chain imbalance is present when significant difference is identified between the perception of the first supply chain partner of the contribution of the second supply chain partner to the performance of the first supply chain partner and between the perception of the second supply chain partner of the contribution of the third supply chain partner to the performance of the second supply chain partner (S and FM C or C and FM_S).

We can further differentiate supply chain imbalance depending on whether it occurs downstream or upstream. Upstream supply chain imbalance is present when the perceived contribution of customer to food manufacturer's performance (FM_C) significantly differs from the perceived contribution of food manufacturer to supplier's performance (S). Downstream supply chain imbalance is present when the perceived contribution of a supplier to a food manufacturer's performance (FM_S) significantly differs from the perceived contribution of the food manufacturer to the customer's performance (C).

Definition: Bias is present in the supply chain, when a member holds differing evaluation of upstream vs. downstream partner contribution to performance.
For example, when significant difference is identified between the perception of one agent (FM) about the contribution of its two supply chain partners (up and downstream) (S and C) to the performance of that one agent (FM). It is also present, when the perception of two different supply chain members (S and $\mathrm{C}$ ) significantly differ regarding the contribution of a third agent (FM) to the performance of that one agent.

As such, bias can be further differentiated. Internal bias is present, when the perceived contribution of supplier to food manufacturer's performance (FM_S) significantly differs from the perceived contribution of customer to food manufacturer's performance (FM C). External bias occurs when perceived contribution of food manufacturer to supplier's performance (S) compared with perceived contribution of food manufacturer to customer's performance (C) significantly differs.

It has to be noted that the direction of the "contribution" and not the direction of the "perception" is taken into account when compiling the above classification of the different comparisons. Therefore upstream (back to source, back to supplier) refers to the contribution of customer to food manufacturer's performance (FM_C) 
together with the contribution of food manufacturer to supplier's performance (S). Furthermore, the comparisons are carried out by computing the differences between the scores of the perceived contribution of the different supply chain members. Therefore, difference scores are computed for dissonance based on FM S minus S (FM and $\mathrm{S}$ dissonance) and based on FM_ $\mathrm{C}$ minus $\mathrm{C}$ (FM and $\mathrm{C}$ dissonance), for supply chain imbalance based on FM_C minus S (upstream supply chain imbalance) and based on FM_S minus C (downstream supply chain imbalance), for bias based on based on FM_S minus FM_C (internal bias) and based on S minus $\mathrm{C}$ (external bias).

Logically, each difference can result in a zero, a negative or a positive score. For example, when considering FM and $\mathrm{S}$ dissonance a positive score is obtained when
FM S is higher than $\mathrm{S}$. This means that the perceived contribution of supplier to food manufacturer's performance (FM_S) is higher than the perceived contribution of food manufacturer to supplier's performance (S). Similarly, in case FM_S is lower than S, a negative score is obtained, meaning that the perceived contribution of supplier to food manufacturer's performance (FM_S) is lower than the perceived contribution of food manufacturer to supplier's performance (S). In case of equal perceptions, the difference is zero. Based on differences, we define our measures of dissonance, bias, and supply chain imbalance as the absolute value of differences. This results in a measure interpretable as the distance between assessments. Table 2 presents the differences of medians for each item and construct.

Table 2.

Supply chain performance imbalances, differences of medians $(n=213)$

\begin{tabular}{|c|c|c|c|c|c|c|}
\hline & \multicolumn{2}{|c|}{ Dissonance } & \multicolumn{2}{|c|}{ Supply chain imbalance } & \multicolumn{2}{|c|}{ Bias } \\
\hline & $\mathrm{FM}$ and $\mathrm{S}$ a & $\mathrm{FM}$ and $\mathrm{C} \mathrm{a}$ & Upstream & Downstream & Internal & External \\
\hline Performance & \multicolumn{2}{|c|}{ Differences of Medians } & \multicolumn{2}{|c|}{ Differences of Medians } & \multicolumn{2}{|c|}{ Differences of Medians } \\
\hline Traditionalism & 0 & -0.10 & -0.10 & 0 & 0.10 & 0 \\
\hline Authenticity & 0 & 0 & 0 & 0 & 0 & 0 \\
\hline Gastronomic heritage & 0 & 0 & 0 & 0 & 0 & 0 \\
\hline Efficiency & 0 & 0.10 & 0 & 0.10 & 0 & 0.10 \\
\hline Logistic cost & 0 & 1 & 0 & 1 & 0 & 1 \\
\hline Profit & 0.10 & 0 & 0 & 0 & 0 & 0 \\
\hline Responsiveness & 1 & 0.50 & 0 & 1 & 0.10 & 0.50 \\
\hline Lead time & 0 & 0 & -1 & 1 & 1 & 1 \\
\hline Customer complaints & 0 & -1 & -1 & 0 & 1 & 0 \\
\hline Quality & 1.0 & -1 & 0 & 0 & 1 & -1 \\
\hline Safety & 1.0 & -1 & -1 & 1 & 2 & 0 \\
\hline Attractiveness & 0.50 & 0 & 2 & -1.10 & -1.10 & -2 \\
\hline Environmental friendliness & 0.50 & 1 & 0 & 1.50 & 0.50 & 1 \\
\hline Supply chain balance & 0 & 0.50 & 0.50 & 0 & 1 & 0 \\
\hline Distribution of risks \& benefits & 0 & 0 & 0 & 0 & 0 & 0 \\
\hline Supply chain understanding & 0 & 1 & 0 & 0 & 0 & 0 \\
\hline Total & 1 & 0 & 0 & 0 & 1 & 0 \\
\hline
\end{tabular}

Note: a $\mathrm{FM}=$ Food manufacturer, $\mathrm{S}=$ Supplier, $\mathrm{C}=$ Customer.

\section{RESULTS}

\section{Supply chain performance imbalances}

Looking across results, all three types of supply chain performance imbalances can be identified (table 1) regarding the overall performance. The significant difference between FM_S and S indicates that the perception of the food manufacturer and the supplier differs regarding the extent to which they contribute to each others' performance. Food manufacturers perceive their suppliers' contribution to their performance higher than the other way around (FM_S and S dissonance). Furthermore, the significant difference between FM_S and FM_C indicates that the perception of the food manufacturer on the extent to which his supplier (S) contributes to his performance is higher than the extent to which his customer (C) contributes to his performance (Internal bias). Finally, higher FM_S than C difference suggests that the supply chains investigated are characterized by downstream supply chain imbalance, whereas the perceived contribution of supplier to food manufacturer's performance (FM_S) is significantly higher than the perceived contribution of food manufacturer to customer's performance $(\mathrm{C})$. To understand the underlying differences, the three main imbalances constructs are considered for each of the five performance constructs.

\section{Dissonance}

FM_S and $\mathrm{S}$ dissonance is identified regarding efficiency (logistic cost), quality (safety), while FM_C and C dissonance is found regarding supply chain balance (supply chain understanding). FM_S and S dissonance on efficiency (logistic costs) suggests that the extent to which food manufacturers perceive the contribution of their suppliers to lowering their logistic costs significantly differ from the extent to which suppliers perceive the contribution of the food manufacturers to lower their logistic costs. The descriptive comments made during the interviews explain some of the hindrances to collaborative practices in the logistic channel. It is a common practice that suppliers bring the raw materials to the site of the food manufacturers, or the food manufacturers are often located near the suppliers (e.g. dairy farmers 
being closely located to the traditional cheese processing plant). Suppliers often provide additional services by being responsible for transport of raw materials. Furthermore, it happens frequently that suppliers harvest the raw materials, and their lorries have to wait at the factory entrance because of disorganization at the level of the food manufacturers.

FM_S and S dissonance regarding quality (safety) indicates that the perceived extent to which suppliers contribute to managing product safety of the food manufacturers (and especially to) is higher than the extent to which food manufacturers contribute to managing product safety of the suppliers. This perceived performance corresponds to reality, whereas the raw material suppliers' role and responsibility in the safety or environmental friendliness of the final manufactured product is much higher than the other way around. Suppliers' perception about the extent to which food manufacturers help them to manage safety is lower. The reason can be that in today's word of series of food scandals, if anything in the agri-food sector goes wrong, the media and the public are immediately involved. Therefore food is a critical item, it can be nothing less than completely safe (Woerkum and Lieshout, 2007) which requires each supply chain members' contribution, however, the suppliers' contribution to it is still perceived higher than the contribution of later agents in the supply chain.

FM C and C dissonance shows a significant perceptual difference between the food manufacturers and their customers regarding supply chain understanding. This refers to the fact that food manufacturers' perception regarding their customers' contribution to better understanding other supply chain members' interests is higher than vice versa. This higher score can refer to the fact that customers hold important market information which could help food manufacturers to understand e.g. consumers' preferences. Food manufacturers also hold important information coming from the previous agents in the supply chain; however customers do not attach such high importance to this.

\section{Supply chain imbalance}

Upstream supply chain imbalance is present regarding quality (attractiveness) (significant difference between FM_C and S), while downstream supply chain imbalance is present regarding efficiency (logistic cost), responsiveness (lead time), quality (safety, attractiveness) and supply chain balance (supply chain understanding) (significant difference between FM S and C). Upstream supply chain imbalance (FM_C - S) regarding quality (attractiveness) shows that food manufacturers consider customers' contribution (FM C) in helping them to produce more attractive products higher than suppliers consider food manufacturers' contribution (S). Some examples of customers helping food manufacturers to produce more attractive products would be for instance providing valuable feedback to food manufacturers about consumers' preference, or even providing promotional shelf space or regional corner for traditional food manufactures, or financing product line extension. It seems that the contribution to more attractive products is more relevant between the food manufacturers and the customers than between the food manufacturers and the suppliers.
Downstream supply chain imbalance (FM_S and C) regarding logistic costs suggest customers evaluating food manufacturers' contribution to lowering their logistic costs as less significant than food manufacturers do in relation to their suppliers. Customers' perception regarding the food manufacturers' contribution to lowering logistics costs are lower than food manufactures' perception regarding the suppliers' contribution. This confirms the reliance of the food manufacturers on both suppliers and customers in terms of logistic services because of the poor distribution systems of food manufacturers.

Downstream supply chain imbalance (FM_S and C) regarding lead time reveals that food manufacturers are the weakest links within the supply chain when it comes to reducing lead time. It means that the time interval between getting request from the food manufacturers for raw material till sending reply or delivery is acceptably short according to the food manufacturers. As a result, food manufacturers perceive the extent to which their suppliers help them to reduce lead time significant. This can be explained by the fact that the kind of businesses these companies are involved in require short lead times, for instance in case of a milk supplier and a cheese manufacturer, delivery appointments are crucial. Furthermore, the partnership relationship between suppliers and food manufacturers also would support improved lead time (Fawcett, 1992). However, when we move further downstream on the supply chain, the customers' perception on the extent to which the food manufacturers help them in order to reduce lead time is significantly lower. Customers pressure food manufacturers to reduce lead time, but still, the manufacturing lead-times at the level of the food manufacturers - which are linked with delivery lead time - are often very long. This of course further influences the customers' ability towards the final consumer or towards other customers to perform well.

Downstream supply chain imbalance (FM_S and C) regarding safety and attractiveness shows an interesting picture. Food manufacturers' perception about the extent to which suppliers help them in order to manage product safety is higher than customers' perception on the extent to which food manufacturers help them to manage product safety. Does it mean that the food manufacturer is the weakest link within the supply chain in terms of safety? Or does it mean that customers "put their face" in the spot light, towards the consumers, and perceive the importance of safety much higher? And therefore have higher expectations? And can food manufacturers meet these expectations with more difficulties than suppliers meeting food manufacturers' expectations? Anyhow, the raw material suppliers' role and responsibility with regard to the safety of the final manufactured product is critical, and they seem to perform accordingly, while there are more critiques at the downstream side of the supply chain. Interestingly, when it comes to attractiveness, the picture looks different. Food manufacturers' perception about the extent to which suppliers help them to manage product safety is higher than customers' perception about the extent to which food manufacturers help them to manage product safety. Logically, the raw material suppliers' role and responsibility in helping the producers 
to produce more attractive final products is much lower than the food manufacturers' role. As such, although supply chain imbalance exists both for safety and for attractiveness, lower performance is experienced at the level of the food manufacturers related to safety, and at the level of the suppliers related to attractiveness.

Downstream supply chain imbalance (FM_S and C) regarding supply chain balance (supply chain understanding) shows that it is not equally important at the different levels of the supply chain for supply chain partners to understand each others' interest.

\section{Bias}

Internal bias can be observed regarding quality (safety, attractiveness) (significant difference between FM C and FM C), while external bias regarding quality (attractiveness) (significant difference between $\mathrm{S}$ and $\mathrm{C}$ ).

The difference perception of the food manufacturers about the extent to which their suppliers and their customers help them to manage product safety or to produce more attractive products confirms what has been said before. The raw material suppliers' role and responsibility in the safety of the final manufactured product is higher than the customers' role in it. All what customers do is obliging food manufacturers to comply with regulations and standards on safety, but food manufacturers do not consider this as a significant help. As for attractiveness, the pictures looks different, and customers score higher than suppliers.

Finally, external bias regarding attractiveness also confirms what we already explored, namely that suppliers' perception about the extent to which food manufacturers help them to produce more attractive products is less relevant than for customers.

\section{CONCLUSIONS}

The aim of this article was to contribute to the understanding of the role of intermediary organizations, and especially of network administrative organizations (NAOs) in the development of social capital in interorganizational networks in the food sector in particular. Our study shows that there are many options available to NAOs to build social capital within the networks they are responsible for; options which we propose to categorize in three main distinct groups. First, NAOs may nurture the development of social capital within the network through creating 'space' boundary objects which appear, in our study, to be an absolute precondition for the development of interactions and hence creation of ties between network members. Second, NAOs may impact the development of social capital by favoring certain members - or set of members - over others due to their characteristics such as good reputation, possession of common past experiences, multidisciplinary experiences, non-conflicting goals, similarity in terms of sector of activity and/or experience level and common mindset towards information exchange. Third and finally, NAOs may foster social capital development by enhancing effective communication between members on the one hand, and between members and the NAOs' coordination and decision bodies on the other hand, via a clear mandate, network decision making bodies composed of members, the use of ex-post evaluations and formal governance mechanisms (e.g. legal contracts), and the selection of staff endowed with a proactive and perspective taking behavior and able to show neutrality when conflict arise.

In the frame of this chapter, we measured traditional food supply chain performance and identified supply chain performance imbalances. Therefore, we collected quantitative data via individual interviews with 270 companies from 3 European countries (Belgium, Hungary, Italy) representing 5 traditional food subsectors (cheese, beer, white pepper, dry sausage, bakery, and ham). We measured traditional food supply chain performance by asking respondents (suppliers, food manufacturers and customers) about the extent to which they agree or disagree with 11 statements on 5 main categories of supply chain performance using a seven-point response scale ranging from completely disagree (1) to completely agree (7). Thus, each food manufacturer provided evaluation scores with respect to their individual supplier and customer contributions to that food manufacturer's economic performance. Similarly, each supplier/customer provided item responses that indicate their assessment of the food manufacturer's contribution to that supplier's/ customer's performance.

We found that all three types of supply chain performance imbalances can be identified regarding the overall performance, namely bias, supply chain imbalance and dissonance. These imbalances found their reflection in the state of the art scientific literature, especially in balance theory and structural hole concepts. Choi and $\mathrm{Wu}$ (2009) suggest that a balanced state offers a stable relational structure for the supply chain members. It signifies a state of equilibrium, where all members of the triad consider the overall relationship arrangement as being equitable. An unbalanced state reflects inequity and brings instability for supply chain members. To the extent that relational uncertainty is posed on the supply chain members, which costs additional resources when dealing with each other, the pressure is there to reduce such uncertainty and move toward a balanced state. Our supply chain imbalances however do not consider balances and imbalances in supply chain relationships, but in supply chain performance. As such, we observed internal bias regarding quality (safety, attractiveness) external bias regarding quality (attractiveness), upstream supply chain imbalance regarding quality (attractiveness), downstream supply chain imbalance regarding efficiency (logistic cost), responsiveness (lead time), quality (safety, attractiveness), supply chain balance (supply chain understanding), FM_S and S dissonance regarding efficiency (logistic cost), quality (safety), and last but not least FM_C and C dissonance regarding supply chain balance.

The results present extensive comparison of multiple individual supply chains. Per individual supply chain it looks into the nature of imbalances being present. These findings create an opportunity for improvement through rigorous comparison of supply chain members' performance. It allows the identification of the weakest link, as well as supply chain members and policy makers to make specific and tailor-made efforts to enhance performance at specific location of the supply chains, depending on the type of imbalance. The shift to analysis of individual supply chains, horizontal comparison of supply 
chains and identification of supply chain commonalities may contribute to develop a new management theory. Some limitations of the chapter are worth mentioning.

Firstly, the chapter is limited in its scope with regard to the research setting (countries and TFP categories) and the unit of analysis (supply chain). With regard to the former, the number of countries and TFP categories involved in the research was limited due to time and budgetary constraints. Regarding the latter, the chapter defines supply chains in a narrow sense (three members), therefore the identified perceptions represent the perspectives of a limited number of supply chain members (suppliers, food manufacturers, customers). Were the definition to be widened, input from additional members would be necessary (suppliers of suppliers, customers of customers, third parties, competitors etc). Nevertheless, although the scope is narrow, it is appropriate for the objective character of this chapter. Secondly, the suggested types of supply chain performance imbalances are developed based on the full consideration of the nature of the data set, and not based on prior considerations from the literature. Consequently, even though the developed types of supply chain performance imbalances are rooted in scientific literature, they rather possess a methodological origin than a theoretical one.

Future research could repeat the applied methodology in other, both food and non-food, sectors. Besides, it should conceptualize the identified performance imbalances by grounding it deeper in theory dealing with relationship economics. Finally, additional comparison of individual supply chains should be carried out to generate hard evidence from which innovative management theory might be developed.

\section{ACKNOWLEDGMENT}

This article was prepared under the framework of the TRUEFOOD (Traditional United Europe Food) project. TRUEFOOD is an integrated project financed by the European Commission under the $6^{\text {th }}$ Framework Programme for RTD (Contract no. FOOD-CT-2006016264). The information in this document reflects only the authors' views; the Community is not liable for any use that may be made of the information contained therein. The authors are grateful for all the partners of WP1 and WP5 for their contributions.

\section{REFERENCES}

Aramyan, L. H. (2007): Measuring supply chain performance in the agri-food sector. Wageningen University. Wageningen. 144.

Beamon, B. M. (1998): Supply chain design and analysis: Models and methods. International Journal of Production Economics. 55. 3: 281-294

Beamon, B. M. (1999): Measuring supply chain performance. International Journal of Operations \& Production Management. 19. 3: 275-292.

Choi, T. Y.-Wu, Z. (2009): Triads in supply networks: theorizing buyer-supplier-supplier relationships. Journal of Supply Chain Management. 45. 1: 8-25.

Christopher, M. (1998): Logistics and supply chain management: strategies for reducing cost and improving service. Financial times. London.

Clare, B.-Shadbolt, N.-Reid, J. (2002): Supply Base Relationships in the New Zealand Red Meat Industry: A Case Study. Fifth International Conference on Chain and Network Management in Agribusiness and the Food Industry. Noordwijk. Wageningen Academic Publishers.

Collins, A.-Henchion, M.-O'Reilly, P. (2001): Logistics customer service: performance of Irish food exporters. International Journal of Retail \& Distribution Management. 29: 6-15.

Cox, A. (1999): Power, value and supply chain management. Supply Chain Management: An International Journal. 4. 4: 167-175.

Fawcett, S. E. (1992): Strategic logistics in co-ordinated global manufacturing success. International Journal of Production Research. 30. 5: 1081.

Gellynck, X.-Vermeire, B.-Viaene, J. (2006): Innovation and networks in the food sector: Impact of regional factors. $99^{\text {th }}$ EAAE Seminar on 'Trust and Risk in Business Networks,. University of Bonn. Germany.

Gunasekaran, A.-Patel, C.-McGaughey, R. E. (2004): A framework for supply chain performance measurement. International Journal of Production Economics. 87. 3: 333-347.

Gunasekaran, A.-Patel, C.-Tirtiroglu, E. (2001): Performance measures and metrics in a supply chain environment. International Journal of Operations \& Production Management. 21. 1-2: 71-87.

Kaplan, R. S. (1983): Measuring Manufacturing Performance: A New Challenge for Managerial Accounting Research. Accounting Review. 58. 4: 686
Lambert, D. M.-Cooper, M. C. (2000): Issues in Supply Chain Management. Industrial Marketing Management. 29. 1: 65-83.

Lambert, D. M.-Pohlen, T. L. (2001): Supply Chain Metrics. International Journal of Logistics Management. 12. 1: 1-19.

Li, D.-O'Brien, C. (1999): Integrated decision modelling of supply chain efficiency. International Journal of Production Economics. 59. 1-3: 147-157.

Lu, H.-Trienekens, J. H.-Omta, S. W. F. (2006): Does Guanxi Matter for Vegetable Supply Chains in China? A Case Study Approach. $7^{\text {th }}$ International Conference on Management in AgriFood Chains and Networks. Ede. The Netherlands.

Neely, A.-Gregory, M.-Platts, K. (1995): Performance measurement system design: A literature review and research agenda. International Journal of Operations \& Production Management. 15. 4: 80-116.

Neely, A.-Mills, J.-Platts, K.-Gregory, M.-Richards, H. (1994): Realizing Strategy through Measurement. International Journal of Operations \& Production Management. 14. 3: 140-152.

Pearson, M.-Samali, A. (2005): Offsite Solution Delivery Centers Increasingly Important to High-performance Supply Chains. Outlook. Point of View January.

Spekman, R. E.-Kamauff, J. W. Jr.-Myhr, N. (1998): An empirical investigation into supply chain management: A perspective on partnerships. International Journal of Physical Distribution \& Logistics Management. 28. 8: 630-650.

Van der Vorst, J. G. A. J. (2000): Effective food supply chains: generating, modeling and evaluating supply chain scenarios. Wageningen University. Wageningen. 305.

Van Der Vorst, J. G. A. J. (2006): Performance Measurement in Agri-Food Supply-Chain Networks. Logistics and Operations Research Group. Wageningen University. Wageningen. 14-24.

Woerkum, C. M. J. von-Lieshoutv, I. M. von (2007): Reputation management in agro-food industries: safety first. British Food Journal. 109. 5: 355-366.

Zhenxin, Y.-Hong, Y.-Cheng, T. C. E. (2001): Benefits of information sharing with supply chain partnerships. Industrial Management \& Data Systems. 101. 3: 114-121. 
